https://www.proliteracy.org/Portals/O/pdf/Research/ALE\%2OJournal/ALE_ResearchJournal-v003_02-2021-44_Miles.pdf

\title{
Adult Education: A State Director's Perspective Where Are We Now? Where Are We Headed?
}

Trenia Miles, State Director

Division of Workforce Services, Adult Education Section, Arkansas

Since 1964, adult education has played a pivotal role in helping adults improve their lives and advance economically. According to the Federal Adult Education-A Legislative History, 1964-2013, when an influx of immigrants started arriving in the United States in the $20^{\text {th }}$ century, language became a barrier for many to fully participate in the work and economic opportunities the country began to offer (Eyre \& Pawloski, 2014). In response, states met this challenge by providing instruction to help immigrants learn English. Today, the field of adult education continues the pattern of evolving to meet the needs of its respective community and the nation. For example, family literacy classes are offered to help improve the economic outlook of families and assist parents in supporting their children's academic needs. Workplace classes provide an opportunity for employees to improve basic academic skills and increase work productivity on the job. Additionally, correctional education gives those in institutional settings a chance to earn their high school equivalency diploma so that, upon release, they can reenter society and increase their chances of obtaining a job.

When adult education centers closed during COVID-19 pandemic, the adult education community found itself evolving once again, in unexpected ways, as teachers found creative ways to continue providing instruction to students. For instance, teachers held classes outside in parking lots, delivered course work to students at their homes, and provided academic assistance and instruction both synchronously and asynchronously. The adversity of the moment revealed the character-one of resiliency, ingenuity, and adaptability - of the adult education community. Since students were no longer physically coming to the adult education centers due to the spread of COVID-19, programs experienced a decline in student enrollment compared to the previous fiscal year. For example, during the 2019-2020 program year, close to 22,000 Arkansans came to the adult education center for services, which is a $5 \%$ decrease compared to the previous year. As of February 2021, student enrollment in adult education centers across the state is 3,365 compared to 6,448 students during this same time period in 2020, prior to COVID-19. The question of the hour is how to continue to adapt to an environment in which student enrollment is at an all-time low. An approach to consider is one that comprehensively fosters student-centered environments, provides professional development for teachers, promotes adult education, and builds and expands partnerships. 


\section{Impact of the COVID-19 Pandemic on Adult Learners}

The COVID-19 pandemic has shown us the increasing economic and physical vulnerability of many Americans. We have also witnessed a surge in poverty, housing insecurity (e.g., evictions and homelessness), food insecurity (e.g., hunger and food access issues), long-term unemployment, and challenges with health care access and use. While these hardships transcend demographics (e.g., age, race, ethnicity, gender, socioeconomic status, etc.), workers without a high school diploma or from a lower socioeconomic background are often the ones most adversely impacted. This is partially due to the tendency of this population to work in service industry jobs (e.g., food service, delivery, hospitality, retail, etc.) - many of which closed to minimize or stop the spread of COVID-19-where instability and unpredictability are common. Just as employment access can be problematic for this population, especially during the current pandemic, education access can also be challenging. Prior to the COVID-19 pandemic, competing factors, such as family, work, and school, routinely played a role in adult learners frequently starting and stopping their educational journey. With the presence of COVID-19, many parents made the difficult decision to leave the workforce for generally either safety reasons, to help their children with remote learning, or because childcare was not available. Many adult learners were also unable to attend class, especially during the day, for the same reasons. Overall, it is understandable that the priorities for much of this population has shifted increasingly from education to basic survival.

In the hierarchy of needs, Maslow (1943) describes the first two basic human needs as physiological and safety. Physiological needs include the need for food, water, and shelter, whereas safety needs include having job security and being free from harm. Adult learners who suddenly find themselves unemployed with limited or nonexistent financial resources available are more likely to be primarily concerned with survival, rather than with attending school. Being aware of these dynamics, and how they often contribute to the decline in student enrollment, may aid adult education providers and administrators in better leveraging tools and resources to provide more student-centered education that potentially minimizes the impact of disruptions to the education process.

\section{Student-Centered Environment}

When the adult learner fails to attend class consistently or stops attending altogether, the common perception is that they are lacking motivation or are not committed to their educational goals. Although this may be true for some, the reasons adult learners may fail to attend class consistently is as diverse as the adult learner. Nonetheless, judgments about why the adult learner stops attending classes seem to be based more on assumptions, rather than facts gleaned from direct conversation with the adult learner. As such, assisting adult learners may first require suspension of judgment and redirecting focus to cultivating a student-centered environment, where the needs of the adult learner are central.

This also includes strategically considering when and where classes are offered, how often they are offered, who participates, and what polices and/ or practices support or hinder the adult learner in completing their educational goal. The hours of operation for many adult education centers are an example of a factor that determine who can participate in the education process and when that can occur. Although programs offer some evening classes, the bulk of student attendance happens during the day. 
Offering distance learning is an example of how adult education programs can become more student centered. Students who are unable to attend school due to family and work responsibilities can continue their education with little or no interruptions. When centers closed due to the pandemic, student enrollment was negatively impacted. Distance learning became a viable solution to help combat declining enrollment, but not without challenges. In general, both teachers and students lacked the basic digital literacy skills to successfully navigate and implement online learning. Other challenges faced by staff and students were broadband and internet access, especially in rural or remote areas. Adult education centers whose teachers were trained and equipped to teach online were able to retain some of its students through distance learning. Despite the availability of distance learning, student enrollment remains low due to the pandemic.

Distance learning may become an integral part of how adult education operates beyond the pandemic. Consider the number of colleges that offer online degrees as an option for the working adult. Why should adult education be any different? During the pandemic, many programs have allowed adult learners to complete the intake form and orientation process online, complete pre- and post-test using a remote proctor, receive instruction virtually, and take the high school equivalency exam without coming physically to an adult education center. Many barriers could be removed if more adult education programs began to virtually offer, as a possibility, the entire high school equivalency process from start to finish. Of course, distance learning is not for all students, but it is certainly a viable option for those who are self-directed and time conscious. Unfortunately, distance learning may not always address the issue of access. For example, students who are motivated, but lack the financial resources to purchase a computer and internet access, may not be able participate in distance learning opportunities. Although distance learning allows students to access education remotely and improve their odds of moving forward, some students will still be at a disadvantage due to the lack of resources. During the pandemic adult education centers purchased Chromebooks and laptops with data cards for students to check out to use, but due to limited financial resources, programs were only able to purchase a few. Therefore, students who had access to the internet were able to continue their participation in adult education.

The pandemic made the digital divide very concrete, especially for those who are of lower socioeconomic status or who live in rural communities. Students who have wanted to continue their education during COVID-19 are unable to do so remotely if they have neither the digital literacy skills needed to navigate learning remotely, nor the access to technology. This issue will need to be addressed if online learning is to be fully accessible and sustainable for all learners.

\section{Professional Development for Teachers}

In order to adequately foster a student-centered environment, it is important that adult education center staff are knowledgeable or equipped with the resources and services that are readily available to assist these learners. Staff may have professional development needs that go beyond instruction. They may also require professional development in areas such as distance learninghow to integrate technology into the curriculum, as well as how to use it. The pandemic brought to the forefront the lack of distance learning preparation in our learning centers. Since centers were not initially holding face-to-face classes during the pandemic, distance learning provided 
a great learning alternative for those students that could and were willing to access it.

Although the number of teachers trained in distance learning has increased, they continued to struggle not only with navigating remote learning, but also utilizing educational technology tools. Teachers wanted to learn how to integrate technology, but it was challenging for many of them to learn it remotely, especially if they had fears regarding technology. The ability to successfully implement distance learning is an area for improvement for many adult educators.

Although digital literacy skills should be integrated into the curriculum, providers must ensure that basic technology skills are an integral part of the student academic program given that many students also lack digital literacy skills and/ or do not have access to technology. Teachers must also demonstrate their ability to integrate technology into the curriculum even if classrooms return to normal. We know that digital literacy is a necessary $21^{\text {st }}$ century skill set for many employers. Therefore, it is important that both staff and students have basic technology skills.

\section{Promoting Adult Education and Building Partnerships}

Under the Workforce Innovation and Opportunity Act, adult education plays an important role in the workforce development system. Although earning a high school equivalency diploma is a critical part of upward mobility, it is only one of many steps toward economic sustainability. Adult education needs to be able to offer more to learners. Recall that adult learners are constantly prioritizing based on competing life factors. Not only must we give adults a reason to come to our centers, but we must also give them a reason to stay that does not conflict with external responsibilities.
Many of our adult learners are facing economic hardships. Businesses that closed during the pandemic have no plans of reopening, which means that for some Americans, they no longer have a job. While some jobs are not coming back, new jobs, which require higher skill levels, have been created. Adult education centers could utilize employment needs as an opportunity to recruit and retain students by marketing workforce preparation and training along with academic skills instruction.

Adult learners often need assistance with transportation and childcare and are experiencing housing and food insecurities. By establishing bidirectional partnerships with social service programs, such as the Supplemental Nutrition Assistance Program Employment and Training, Temporary Assistance for Needy Families, Housing for Urban Development, and Title I Adult, Dislocated Worker, and Youth Program, we can help reduce barriers for the adult learner, which makes completing a high school equivalency diploma possible. In turn, these partnerships can ensure that populations accessing the abovementioned services are able to obtain information about and access to wraparound services that include adult education.

\section{Final Thoughts on the Direction of Adult Education}

Adult education is a field that continues to evolve over time. The coronavirus pandemic has impacted us both personally and professionally, while at the same time, it has given us an opportunity to evaluate who we are and where are we going as a profession. As many have witnessed, student enrollment has significantly declined during the pandemic. Yet, we know that students need our services even more now in these economically challenging times. 
How do we redesign adult education without changing the essence of who we are? What should be the core of our focus? Are there policies that serve as a barrier to adult education programs and learners that need to be eliminated or modified? How can we maximize our resources in a costeffective manner?

What services, support, and strategies can adult education provide that will reduce or eliminate barriers for students? Instead of adding to the angst of our learners in making them choose between other competing factors, how can we best support adult learners so that they are able to address their basic physiological and safety needs and continue their education with as minimal disruption as possible?

Adult learners want to be able to provide for their families but may not always have the means or the know-how to do so. Adult education professionals can bridge this gap by being more student-centered in providing educational services students truly need in ways that are as supported and accessible as possible. Time is the adult student most precious resource. Besides helping the adult learner improve basic academic skills, we need to be asking what additional resources and support can we provide them that will also help increase our retention and inevitably, their success?

As a State Director, maintaining a positive attitude and being flexible are two attributes that have helped during this pandemic. It is also important to be supportive and encouraging to providers as they are working very hard to meet the needs of students. None of us has all the answers and most are learning as we go. We do not truly know how long this pandemic will last or if life will ever go back to normal. However, what I do know is that life goes on and we are no stranger to challenges in the adult education field. We will continue to evolve and meet the needs to today's learners. 


\section{References}

Eyre, G. A., \& Pawloski, R. (2014). Federal adult education: A legislative history 1964-2013. NOVA Research Company.
Maslow, A. H. (1943). A theory of human motivation. Psychological Review, 50(4), 370. 